\title{
OUT OF HOSPITAL CARDIAC ARREST IN WOMEN IN VOJVODINA-EPIDEMIOLOGICAL DATA ANALYSIS
}

\section{Kornelija Jakšić Horvat ${ }^{1}$ Mihaela Budimski Snežana Holcer Vukelić}

\begin{abstract}
Sažetak
Cilj:

Analiza epidemioloških podataka vanbolničkog srčanog zastoja kod žena zastupljenog na teritoriji Vojvodine uz uporednu analizu ranije objavljenih studija.

\section{Metod:}

Za metodologiju rada su korišteni podaci registra srčanog zastoja sa teritorije Vojvodine u vremenskom periodu od 1.10.2014. do 1.08.2017. godine. Podaci su prikupljeni u jedinstvenoj bazi Resuscitacionog Saveta Srbije i unešeni od strane glavnih istraživača iz 13 centara. Za analizu postojećih podataka iz baze, korišten je statistički program statistika SPSS
\end{abstract}

\section{Rezultati:}

U posmatranom periodu na teritoriji Vojvodine potvrdeno je ukupno1240 iznenadnih srčanih zastoja od strane lekarskih ekipa hitnih medicinskih pomoći. Mere kardiopulmonalne resuscitacije su započete kod 706 pacijenata, od kojih je 237 (33,56\%) osoba ženskog pola. Prosečna starost žena je bila 68,2 godine. Najmlađa pacijentkinja je imala manje od 1 godine a najstarija 94. Prema etiologiji, kardiovaskularni uzrok je najučestaliji 197 (83\%), dok se respiratorni etiološki uzrok javlja u $15(6,4 \%)$ i nekardiološki uzroci u $23(9,8 \%)$. Traumatski srčani zastoj kao etiološki faktor u našoj analizi kod žena nije registrovan. Prema mestu nastanka srčanog zastoja kod osoba ženskog pola dominira prebivalište $187(88,6 \%)$, zatim ulica $12(5 \%)$, dom za stare $7(3 \%)$, javna ustanova $3(1,2 \%)$ dok ni jedan vanbolnički srčani zastoj kod osoba nije registrovan na sportskim terenima. Svedok - očevidac je započeo KPR pre dolaska ekipa hitne medicinske pomoći kod 44 žene $(18,6 \%)$. Šokabilni inicijalni ritam je zabeležen kod 61 osobe ženskog pola $(25,7 \%)$ dok je uspostavljena spontana cirkulacija (ROSC) kod 74 žene $(31,2 \%)$. Do otpusta iz bolnice je preživelo 12 pacijentkinja $(5 \%)$ a nakon 30 dana $11(4,6 \%)$.

\section{Zakijučak:}

Prema analizi epidemioloških podataka na teritoriji Vojvodine vanbolnički srčani zastoj se ređe javlja kod žena u odnosu na osobe muškog pola. Prosečna starost je veća, srčani zastoj je u nižem procentu osvedočen od strane laika, a primena mera KPR od strane svedoka neznatno učestalija. Registrovan je manji procenat inicijalnog šokabilnog ritma kao i uspostavljanje spontane cirkulacije (ROSC) kao i niže preživljavanje. Dalje analize bi mogle doneti odgovor na razlog češćeg sprovođenja KPR od strane laika kada su u pitanju žene a ipak nedovoljnog za povećanje trenda preživljavanja.

\section{Abstract \\ Objectiver}

analysis of epidemiological data of out of hospital cardiac arrest (OHCA) in women of Vojvodina in comparison to up to date published studies.

\section{Methods:}

In our study we used data from the OHCA register from region of Vojvodina from 01. 10. 2014 to 01. 08. 2017. Data were derived from common database of Serbian Resuscitation Council collected by main researchers from 13 centers. Analysis was performed using statistical program SPSS.

\section{Results:}

In observed period in Vojvodina region, 1240 cases of OHCA were confirmed by Emergency Medical Service (EMS) teams. Cardiopulmonary resuscitation (CPR) was attempted in 706 patients, $237(33.56 \%$ ) of women. Average age of women was 68.2 years. Youngest patient had less than 1 year and eldest was 94 years old. Considering etiology, cardiovascular cause is most common, in $197(83 \%)$ cases, respiratory in $15(6.4 \%)$ and other non-cardiological causes in $23(9.8 \%)$ in women.

Trauma as the cause of OHCA was not found in our analysis was not registered.

Dominant location of OHCA in woman is at home, in $187(88.6 \%)$ cases, followed by public spaces-street in $12(5 \%)$, Nursing Homes in $7(3 \%)$ and public institutions in $3(1.2 \%)$. No cases of OHCA in women were registered on sports fields. Bystander CPR before EMS arrival was registered in $44(18.6 \%)$ of OHCA in women. Shockable rhythm was registered in 61 women ( $25.7 \%$ ). Return of spontaneous circulation (ROSC) was achieved in $74(31.2 \%)$ while $12(5 \%)$ patients were released from hospital alive and 30 days survival was registered in $11(4.6 \%)$.

\section{Conclusion:}

According to epidemiological analysis of OHCA database in woman in region of Vojvodina, we can notice that it is less present than in man. Also, average age of woman with OHCA is grater. OHCA in woman happened less in presence of bystander. Bystander CPR attempt in woman is slightly higher than in man, but presence of shockable rhythm, as well as ROSC and survival to hospital discharge is less.

Detailed analysis of bystanders who start CPR in women OHCA might indicate the reason of their rather willingness to perform it. Still it is not enough to increase survival.

\section{USTANOVA}

Dom zdravlja Subotica

Dom zdravlja Sombor

\section{AUTOR ZA}

\section{KORESPODENCIU.}

Kornelija Jakšić Horvat Dom zdravlja Subotica Petefi Šandora 7

Email: kornelijajaksic@yahoo.com

\section{KLUUČNE REČl:}

vanbolnički srčani zastoj, služba hitne medicinske pomoći, epidemiologija

\section{KEY MORDSE}

Out of Hospital Cardiac Arrest, Epidemiology, Emergency Medical Service
DATUM PRIJEMA RADA

18. decembar 2017. DATUM PRIHUATANA RADA 17. januar 2018. Datum OBIavlumana

20. februar 2018. 


\section{Uvod:}

U literaturi postoje oprečna mišljenja o epidemiološkim podacima i ishodu vanbolničkog srčanog zastoja (VBSZ) u odnosu na polove, a poznato je da se VBSZ češće javlja kod osoba muškog pola (1). Dok jedni autori potvrđuju jednakost u preživljavanju (2), drugi smatraju da je ženski pol povezan sa većom stopom preživljavanja $(3,4)$ dok su treći mišljenja da je preživljavanje niže kod žena (5).

\section{Cilj:}

Analiza epidemioloških podataka vanbolničkog srčanog zastoja kod žena zastupljenog na teritoriji Vojvodine uz uporednu analizu ranije objavljenih studija.

\section{Metod:}

U metodologij rada su analizirani podaci iz registra srčanog zastoja, koji su zabeleženi na teritoriji Vojvodine a koji obuhvataju vremenski period od 1.10.2014. do 1.08.2017. godine. Podaci registra vanbolničkog srčanog zastoja su prikupljeni od strane glavnih istraživača iz 13 centara u jedinstvenoj bazi Resuscitacionog Saveta Srbije. Za analizu postojećih podataka iz baze, korišten je statistički program statistika SPSS.

\section{Rezultati:}

U posmatranom periodu na teritoriji Vojvodine potvrđeno je ukupno1240 vanbolničkih srčanih zastoja od strane lekarskih ekipa hitnih medicinskih pomoći (HMP). Mere kardiopulmonalne resuscitacije (KPR) su započete kod 706 pacijenata (57\%), od kojih je 237 $(33,6 \%)$ osoba ženskog pola,. U tabeli 1. je prikazan Utstain protokol VBSZ kod žena na teritoriji Vojvodine u posmatranom periodu. Prosečna starost žena je bila 68,2 godine. Najmlađa pacijentkinja je imala manje od 1 godine a najstarija 94 godine. Prema etiologiji, kardiovaskularni uzrok je najučestaliji $197(83 \%)$, dok se respiratorni etiološki uzrok javlja kod $15(6,4 \%)$ i nekardiološki uzroci kod $23(9,8 \%)$ žena. Medicinski etiološki uzrok se navodi 225 puta (95\%), asfiksija kao spoljašnji etiološki faktor 3 puta $(1,2 \%)$. Traumatski srčani zastoj (TSZ) kao etiološki faktor u našoj analizi kod žena nije registrovan. Prema mestu nastanaka srčanog zastoja najčešče je prebivalište-187 (88,6\%), zatim ulica 12 $(5 \%)$, dom za stare $7(3 \%)$, javna ustanova $3(1,2 \%)$ dok ni jedan VBSZ kod osoba ženskog pola nije registrovan na sportskim terenima. Svedok - očevidac je započeo KPR pre dolaska ekipa hitne medicinske pomoći kod 44 žene (18,6\%). Šokabilni inicijalni ritam (vetrikularna tahikardija bez pusa VT /ventrikularna fibrilacija VF) je zabeležen kod $61(25,7 \%)$ a nešokabilan ritam (asis- tolija/bezpulsna električna aktivnost PEA) kod 176 žena $(74,3 \%)$. Spoljašnji automatski defibrilator (AED) se ni jednom nije primenio. Povratak spontane cirkulacije (ROSC) je uspostavljen kod $74(31,2 \%)$ žene. Do otpusta iz bolnice je preživelo 12 pacijentkinja (5\%) a nakon 30 dana $11(4,6 \%)$.

\section{Diskusija:}

Analizom epidemioloških podataka (uporedna tabela 2. VBSZ kod muškaraca i žena na teritoriji Vojvodine za 2016. godinu) ustanovili smo da se VBSZ ređe javlja kod žena $(33,6 \%)$, što potvrduju i druga istraživanja sprovedena u različitim zemljama $(6,7,8)$. Žene doživljavaju VBSZ u starijoj životnoj dobi $(7,1)$, prema našem istraživanju u proseku su starije za 4,6 godina. Dalja analiza naših podataka ukazuje da su kardiovaskularne bolesti dominantan etiološki uzrok VBSZ $(83 \%)$ dok su respiratorni i nekardiološki uzroci procentualno duplo više zastupljeni kod žena: respratorni uzroci 6,38\% vs. 3,88\% i nekardiološki uzroci 9,78\% vs.4,75\% . Traumatski srčani zastoj nije registrovan kod žena u ispitanom periodu ( 0 vs. $2,1 \%$ ). Prema mestu nastanka u našoj analizi žene najčešče doživljavaju srčani zastoj u kućnim uslovima (78,9\% vs. $64,6 \%$ ), što je ustanovljeno i ranijim istraživanjima $(9,10)$. Na javnim mestima (posao, javna ustanova, ulica i sportski tereni) žene ređe doživljavaju VBSZ što potvrđuju i drugi autori u svojim istraživanjima $(8,11,12,13)$. Naši podaci ukazuju da ni jedna žena nije doživela srčani zastoj na sportskim terenima. U staračkom domu je veća incidence VBSZ kod žena 3,11\% vs.1,68\% što ide u prilog i starijoj životnoj dobi. Analiza prikupljenih podataka ukazuje da je srčani zastoj nešto ređe osvedočen kod žena $(63,71 \%$ vs. $65,67 \%)$, ali broj započetih mera KPR od strane svedoka pre dolaska ekipa hitne medicinske pomoći je nešto veći-18,56\% vs.14,49\%. Inicijalni šokabilan ritam (pVT/VF) je kod žena zabeležen u nižem procentu $(25,7 \%$ vs $32,40 \%)$ što nije u skladu sa većim brojem započetih mera KPR od strane očevidaca ( $18,56 \%$ vs. $14,49 \%$.). Potrebna je detaljnija analiza zašto je zabeleženo manje šokabilnih ritmova iako je u većem procentu započeta KPR od strane svedoka. Podaci iz literature $(1,8,13,14)$ takode dokazuju da je broj šokabilnih inicijalnih ritmova kod žena manji. Povratak spontane cirkulacije (ROSC) kod žena je uspostavljen u mižem procentu $33,7 \%$ vs. $31,2 \%$ što odgovara manjem broju šokabilnih ritmova kao inicijalnog ritma prema našoj statistici. Preživljavanje do otpusta iz bolnice u posmartanom uzorku je manje kod osoba ženskog pola $5,06 \%$ vs. 6,39\% kao i preživljavanje nakon 30 dana-4,64\% vs.6,39\% što je u suprotnosti sa drugim studijama $(15,16,17)$. Razlike u praćenju po- 
Tabela 1. Utstain protokol vanbolničkog srčanog zastoja kod žena na teritoriji Vojvodine

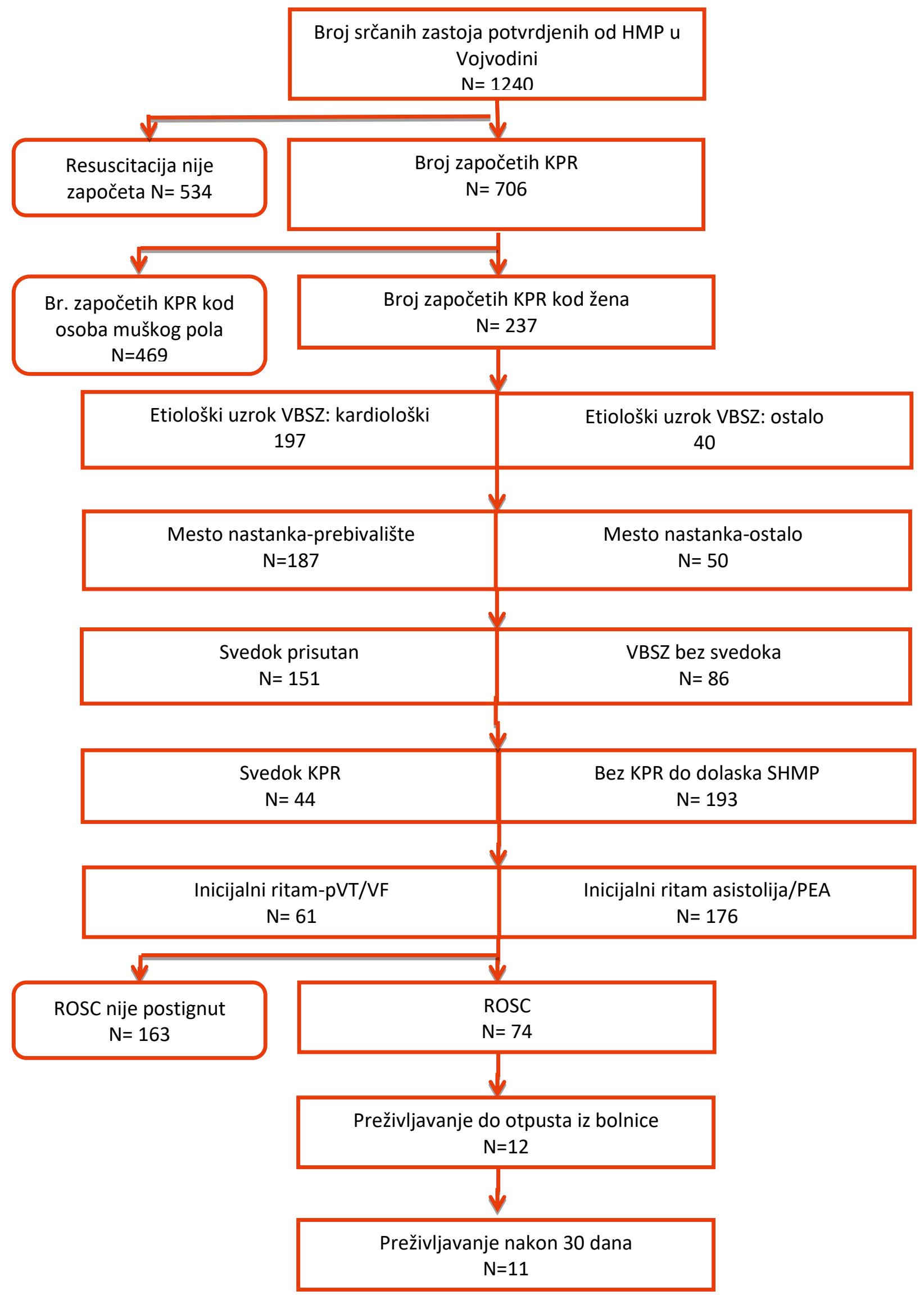


jedinih parametara su neznatne među polovima, te na krajnji ishod najviše utiče blagovremeno započeti KPR, rana defibrilacija, kao i post resuscitaciona nega. Slični podaci su dobijeni OPALS studijom, objavljenom 2014. godine (18). Ista ukazuje da su žene su bile starije od muškaraca (srednja dob 74. godine naspram 69 godina) da je manje osvedočenih srčanih zastoja od strane laika kada su žene u pitanju ( $43 \%$ prema $49 \%$ ), manji broj inicijalni šokabilnih ritmova (12\% vs. $17 \%$ ) i niža je stopa preživljavanja $(1,7 \%$ prema $3,2 \%)$.

\section{Zaključak:}

Prema analizi epidemioloških podataka na teritoriji Vojvodine vanbolnički srčani zastoj se ređe javlja kod žena u odnosu na osobe muškog pola. Prosečna starost je veća, srčani zastoj je u nižem procentu osvedočen od strane laika, a primena mera KPR od strane svedoka neznatno učestalija. Registrovan je manji procenat inicijalnog šokabilnog ritma kao i uspostavljanje spontane cirkulacije (ROSC) kao i niže preživljavanje. Dalje analize bi mogle doneti odgovor na razlog češćeg sprovođenja KPR od strane laika kada su u pitanju žene a ipak nedovoljnog za povećanje trenda preživljavanja.

Tabela 2. Uporedna tabela VBSZ kod muškaraca i žena na teritoriji Vojvodine za 2016. godinu

\begin{tabular}{|c|c|c|}
\hline & $\begin{array}{l}\text { VOJVODINA } \\
\text { ŽENE }(\%)\end{array}$ & $\begin{array}{l}\text { VOJVODINA } \\
\text { MUŠKARCI (\%) }\end{array}$ \\
\hline VBSZ & 1240 & 1240 \\
\hline KPR započet & 706 & 706 \\
\hline pol & $237(33,6 \%)$ & $469(66,4 \%)$ \\
\hline prosečna starost & 68,2 & 63,6 \\
\hline Etiologija: kardiološka & $197(83 \%)$ & $413(88 \%)$ \\
\hline Etiologija: respiratorna & $15(6,3 \%)$ & $18(3,8 \%)$ \\
\hline Etiologija: trauma & 0 & $10(2,1 \%)$ \\
\hline Etiologija:ne kardiološka & $23(9,7 \%)$ & $22(4,7 \%)$ \\
\hline Mesto nastanka: prebivalište & $187(78,9 \%)$ & $303(64,6 \%)$ \\
\hline Mesto nastanka: ulica & $12(5 \%)$ & $60(12,8 \%)$ \\
\hline Mesto nastanka: javna ustanova & $3(1,2 \%)$ & $30(6,4 \%)$ \\
\hline Mesto nastanka: radno mesto & $2(0,8 \%)$ & $13(2,8 \%)$ \\
\hline Mesto nastanka: sportski teren & 0 & $3(0,6 \%)$ \\
\hline Mesto nastanka: dom za stare & $7(2,9 \%)$ & $7(1,5 \%)$ \\
\hline Mesto nastanka: drugo & $26(10,9 \%)$ & $53(11,3 \%)$ \\
\hline Svedok prisutan & $151(63,7 \%)$ & $308(65,7 \%)$ \\
\hline telefonski vođen KPR & $31(13 \%)$ & $53(11,3 \%)$ \\
\hline svedok KPR & $44(18,6 \%)$ & $68(14,5 \%)$ \\
\hline Inicijalni ritam-šokabilan & $61(25,7 \%)$ & $152(32,4 \%)$ \\
\hline ROSC & $74(31,2 \%)$ & $158(33,6 \%)$ \\
\hline Otpušten iz bolnice & $12(5 \%)$ & $30(6,3 \%)$ \\
\hline 30 dana & $11(4,6 \%)$ & $26(5,5 \%)$ \\
\hline
\end{tabular}




\section{Lista skraćenica}

\begin{tabular}{|l|l|}
\hline VBSZ & vanbolnički srčani zastoj \\
\hline KPR & kardiopulmonalna resuscitacija \\
\hline HMP & hitna medicinska pomoć \\
\hline TSZ & traumatski srčani zastoj \\
\hline PVT & ventrikularna tahikardija bez pulsa \\
\hline VF & ventrikularna fibrilacija \\
\hline PEA & električna aktivnost bez pulsa \\
\hline AED & automatski spoljašnji defibrilator \\
\hline ROSC & povratak spontane cirkulacije \\
\hline VS & versus-naspram \\
\hline
\end{tabular}

\section{Reference:}

1. Hasan OF, Al Suwaidi J, Omer AA, Ghadban W, Alkilani H, Gehani A, Salam AM. The influence of female gender on cardiac arrest outcomes: a systematic review of the literature; Curr Med Res Opin. 2014 Nov;30(11):2169-78. doi: 10.1185/03007995.2014.936552.

2. Bray JE, Stub D, Bernard S, Smith K. Exploring gender differences and the"oestrogen effect"

3. in an Australian out-of-hospital cardiac arrest population. Resuscitation. 2013;84:957-63.

4. Adielsson A, Hollenberg J, Karlsson T, Lindqvist J, Lundin S, Silfverstolpe J,et al. Increase in survival and bystander CPR in out-of-hospital shockable arrhythmia: bystander CPR and female gender are predictors of improved outcome. Experiences from Sweden in an 18-year perspective. Heart. 2011;97:1391-6

5. Akahane M, Ogawa T, Koike S, Tanabe S, Horiguchi $\mathrm{H}$, Mizoguchi T, et al. The effects of sex on out-of-hospital cardiac arrest outcomes. Am J Med.2011;124:325-33.

6. Stub D, Smith K, Bray JE, Bernard S, Duffy SJ, Kaye DM. Hospital characteristics are associated with patient outcomes following out-of-hospital cardiac arrest. Heart. 2011;97:1489-94.

7. Nichole Bosson, Amy H. Kaji, Andrea Fang, Joseph L. Thomas, William J. French, David Shavelle, James T. Niemann; Sex Differences in Survival From Out of Hospital Cardiac Arrest in the Era of Regionalized Systems and Advanced Post Resuscitation Care; Journal of the American Heart Association J Am Heart Assoc. 2016 Sep; 15:5(9).

8. Israelsson J, Persson C, Strömberg A, Årestedt K; Is there a difference in survival between men and women suffering in-hospital cardiac arrest? Heart \& Lung: The Journal of Acute and Critical Care 2014;46 (6)510-515.

9. Ng YY, Wah W, Liu N, Zhou SA. et al. Associations between gender and cardiac arrest outcomes in Pan-Asianout-of-hospital cardiac arrest patients: Resuscitation. 2016 May; 102:116-21.

10. Raffay $V$, Tijanić, Fišer Z. Učešće laika u započinjanju kardiopulmonalne resuscitacije. Zašto laici ne pomažu? EuReCa_Srbija. Journal Resuscitatio Balcanica 2017; 7: 41-45.

11. Fišer Z, Vlajović S, Jakšić HK, Raffay V. EURECA Srbija One 2014-vanbolnički srčani zastoj. mesto događaja. Journal

\section{Konflikt interesar}

Autor i koautori izjavljuju da nemaju konflikt interesa.

\section{Zahualnost:}

Autori se zahvaljuju svim učesnicima na pomoći u prikupljanju podataka kao i Resuscitacionom Savetu Srbije.

\section{Finansijska podrška:}

Istraživanje je finansirano od strane Resuscitacionog Saveta Srbije iz sredstava članarine. Autori i koautori nemaju naknadu za učešće u studiji, obradu i saopštavanje rezultata.

Resuscitatio Balcanica 2015; I:9-11.

12. Raffay V, Tijanić J. Srčani zastoj na javnom mestu EuReCa_Srbija. Journal Resuscitatio Balcanica 2017; 8: 58-62

13. Engdahl J, Bång A, Karlson B, Lindqvist J, Herlitz J. Characteristics andoutcome among patients suffering fromout of hospital cardiac arrest ofnon-cardiac aetiology. Resuscitation 2003;57:33-41.

14. Karlsson V, Dankiewicz J, Nielsen N, Kern BK, Mooney $\mathrm{RM}$, et. al. Association of gender to outcome after out-of-hospital cardiac arrest - a report from the International Cardiac Arrest Registry. Crit Care 2015; 19(1): 182.

15. Descatha A, Dagrenat C, Cassan P, Jost D, Loeb T, Baer M.; Cardiac arrest in the workplace and its outcome: a systematic review and meta-analysis.; Resuscitation. 2015 Nov;96:30-6. doi: 10.1016/j.resuscitation.2015.07.004. Epub 2015 Jul 26.

16. Safdar B, Stolz U, Stiell IG, Cone DC, Bobrow BJ et. al. Differential Survival for Men and Women from Out of hospital Cardiac Arrest Varies by Age: Results from the OPALS Study ; Acad Emerg Med. 2014 Dec;21(12):150311. doi: 10.1111/acem. 12540.

17. Lindgren E, Ostlund O, Rubertsson S. Gender differences in outcome and post resuscitation care after out of hospital cardiac arrest. Analysis of the LINC trial. Resuscitation. 2015;96S:101

18. Bougouin W, Mustafic $H$, Marijon E, Murad MH, Dumas F, Barbouttis A, Jabre P, Beganton F, Empana JP, Celermajer DS, Cariou A, Jouven X. Gender and survival after sudden cardiac arrest: a systematic review and meta analysis. Resuscitation. 2015;94:55-60.

19. Safdar B, Stolz U, Stiell I.G. et. al. Differential Survival for Men and Women from Out-of-hospital Cardiac Arrest Varies by Age: Results from the OPALS Study. Academic Emergency Medicine 2014;21:1503-1511. 
